\title{
Definindo boato
}

Defining rumor

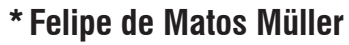

\begin{abstract}
Resumo: Neste ensaio, eu analisarei criticamente três definições de boato. Na primeira seção, eu considerarei a explicação de C. A. J. Coady (2006), na qual o boato é um caso de testemunho aparente, mas não é um caso de testemunho genuíno. Na segunda seção, eu considerarei a definição de boato oferecida por David Coady (2006), na qual o boato se espalha em uma larga cadeia sem status oficial. Na terceira seção, eu considerarei a definição de boato de Axel Gelfert (2013), na qual o boato não tem corroboração independente de evidência de primeira mão ou de fonte oficial. $\mathrm{Na}$ quarta e última seção, eu proporei uma definição, na qual o boato é um caso de testemunho genuíno sem confirmação oficial, cuja fonte original foi perdida ou nunca existiu.
\end{abstract}

Palavras-chave: Testemunho. Boato. Evidência.

\begin{abstract}
In this essay, I will critically analyze three definitions of rumor. In the first section, I will consider the C. A. J. Coady' account (2006), in which the rumor is a case of apparent testimony, but it is not a case of genuine testimony. In the second section, I will consider the definition of rumor offered by David Coady (2006), in which the rumor spreads in a large chain without official status. In the third section, I will consider the definition of rumor of Axel Gelfert (2013), in which the rumor does not have independent corroboration by either firsthand evidence or official sources. In the fourth and last section, I will propose a definition, in which rumor is a case of genuine testimony without official confirmation, whose original source was lost or never existed. Keywords: Testimony. Rumor. Evidence.
\end{abstract}

* Doutor em Filosofia pela PUCRS. Professor no PPG em Filosofia da PUCRS. <matos.muller@ pucrs.br>. 
U m fenômeno antigo, que contemporaneamente tem recebido atenção por parte daqueles que estão discutindo acerca da epistemologia do testemunho, é o boato ${ }^{1}$. Normalmente, em cenários de conflito e tensão social, os boatos tendem a ser propagados (ALLPORT; POSTMAN, 1947, Chapter 1). Com a internet, o seu poder de dissipação se tornou preocupante (SUNSTEIN, 2010, p. 121.). Os boatos geralmente são mal vistos e indesejáveis. Eles são considerados por alguns como uma verdadeira enfermidade comunicacional (COADY, C. A. J., 2006, p. 265). Boatos falsos podem causar todo tipo de dano. Afinal, "os propagadores dos boatos têm motivações diversas. (...) [Alguns] buscam favorecer os próprios interesses prejudicando um indivíduo ou grupo específico" (SUNSTEIN, 2010, p. 17.).

Os boatos tendem a ser propagados por meio de redes informais de comunicação e, por causa disso, podem entrar em conflito com fontes formais de comunicação pública, como a Imprensa ou o Governo. Todavia, fontes formais, neste contexto, não significam fontes confiáveis, apenas fontes encarregadas ou reconhecidas por executar a função social da propagação das informações ao público (GELFERT, 2014, p. 28).

A natureza do boato, é uma questão de epistemologia do testemunho. Definir o que é um boato significa delimitar suas possibilidades e limites do ponto de vista epistêmico. O meu propósito nas seções seguintes é analisar três definições de boato. Um ponto importante a considerar é se o boato é um caso de testemunho. A fim de evitar ambiguidades, vou assumir como pressuposto a visão disjuntivista acerca da natureza do testemunho proposta por Jennifer Lackey (2006, p. 193), na qual " $S$ testemunha que $p$ ao fazer um ato comunicacional a se e somente se (em parte) em virtude do conteúdo comunicável de a, (i) $S$ razoavelmente pretende transmitir a informação de que $p$ ou (ii) a é razoavelmente tomada como transmitindo a informação de que p". Essa definição está baseada sobre a "noção de ato comunicacional, transmitindo a informação que p" e que "requer apenas que o falante pretenda expressar um conteúdo comunicável"2 (LACKEY, 2006, p. 187). Além disso, a definição assegura que o testemunho possa ser entendido tanto como um ato intencional da parte do falante quanto como uma fonte de crença ou conhecimento para o ouvinte.

\footnotetext{
1 A tradução em língua portuguesa assumida para (a) "rumor" ou "rumour" (da língua inglesa) será "boato"; b) para "gossip" será "fofoca"; e (b) para "hearsay" será "rumor".

2 "S testifies that $p$ by making an act of communication a if and only if (in part) in virtue of a's communicable content, (1) S reasonably intends to convey the information that $p$, or (2) a is reasonably taken as conveying the information that $p$ " (LACKEY, 2006, p. 193).
} 


\section{Boato como Testemunho Aparente}

C. A. J Coady (2006, p. 262), em seu "Pathologies of Testimony", caracterizou os boatos como atos de fala com baixo status epistêmico por serem desprovidos de uma "forte base justificacional"3. C. A. J. Coady (2006, p. 265) resume a sua posição acerca dos boatos na seguinte passagem:

Então, o boato é uma enfermidade do testemunho? Parece que é uma forma de testemunho, porque envolve a transmissão de proposições de uma ou mais pessoas para outras (...). Não há, algumas vezes, fontes originárias até mesmo no sentido mais fraco em que observei no meu livro [1992], visto que o boato pode surgir a partir de mera especulação. Além disso, o propagador do boato, muitas vezes, não tem competência no que diz respeito à informação veiculada e pode estar bem ciente disso ${ }^{4}$.

Pode-se formalizar as ideias de C. A. J. Coady do seguinte modo: $\left[\mathrm{B}_{1}\right]$ : S propaga um boato $\mathrm{B}$ se e só se:

(B1) S transmite uma proposição $p$;

(B2) A fonte originária (ou evidência de primeira mão) foi perdida ou nunca existiu;

(B3) S não tem competência ou autoridade (intelectual) acerca da proposição veiculada.

A condição (B1) poderia tipificar um caso de testemunho no sentido disjuntivista. Todavia, C. A. J. Coady, diferentemente, defende o testemunho no sentido restrito ${ }^{5}$. Se boatos fossem casos de testemunho, então o propagador teria "competência relevante, autoridade ou credenciais para declarar realmente que $p$ " (COADY, 1992, p. 62). Contudo, ele observa (no excerto acima) que "[o] propagador do boato, muitas vezes, não tem competência no que diz respeito à informação veiculada". Consequentemente, boatos não são casos de testemunho para C. A. J. Coady. Os boatos tendem a ser casos de testemunho aparente,

3 “(...) rumour has by (my) definition no strong justificatory base" (COADY, 2006, p. 262).

4 "So is rumour pathological testimony? It seems that it is a form of testimony because it involves the transmission of propositions from one or more persons to others, but it often lacks what I have elsewhere claimed to be definitive of testimony. There are sometimes no original sources in even the attenuated senses that I noted in my book since rumour can arise from the merest speculation. Furthermore, the speaker of rumour will often have no competence with regard to the "information" conveyed and may be well aware of that" (COADY, 2006, p. 265).

5 "A speaker S testifies by making some statement $p$ if and only if: (1) His stating that $p$ is evidence that $\mathrm{p}$ and is offered as evidence that $\mathrm{p}$; (2) S has the relevant competence, authority or credentials to state truly that p; (3) S's statement that $\mathrm{p}$ is relevant to some disputed or unresolved question (which may, or may not be, p?) and is directed to those who are in need of evidence on the matter" (COADY, 1992, p. 62). 
mas não casos de testemunho autêntico. As condições requeridas por C. A. J. Coady para termos um caso de testemunho não são apenas muito restritivas, elas conjugam a metafísica com a epistemologia do testemunho, de tal forma que "é impossível ter uma testemunha inconfiável"6 (LACKEY, 2006, p. 180). Por esse motivo, os boatos não se qualificariam como casos de testemunho legítimo.

A Condição (B2) desqualifica epistemicamente o boato, motivando dúvidas acerca da veracidade da proposição transmitida. O boato se dissipa de tal modo, que não se é capaz de reconstruir a cadeia de propagação até a origem. Não é sem motivo que C. A. J. Coady (2006, p. 262) afirma que o boato é, por definição, desprovido de uma "forte base justificacional". Há pelo menos dois pontos de vulnerabilidade epistêmica tratando-se dos boatos: a fonte originária e o processo de transmissão. Pode-se perder a evidência de primeira mão e o processo de transmissão não ser confiável; ou iniciar com uma especulação e o processo de transmissão não ser confiável. Em qualquer caso, o boato parece não trazer consigo propriedades epistêmicas desejáveis, ou por que se perderam no processo de transmissão ou por que, de fato, não havia tais propriedades epistêmicas na origem da cadeia de propagação.

A condição (B3) desqualifica epistemicamente o propagador do boato. Aqueles que propagam boatos tipicamente não são experts sobre o assunto. Embora seja possível pensar em vários graus acerca de quão competente e informada uma pessoa possa ser, C. A. J. Coady parece sugerir que o propagador é um leigo ou novato sobre o domínio na qual a proposição transmitida como boato faz parte. Embora um leigo ou novato possa ter um papel ativo, escrutinando as informações que lhe chegam, ele não funcionaria como um bom "filtro epistêmico".

Pode-se objetar contra a posição de C. A. J. Coady acerca da natureza do testemunho. Afinal, boatos parecem ser casos de testemunho. Contudo, a noção assumida por C. A. J. Coady é muito restritiva. Ela requer que testemunho seja sempre confiável, oferecido por um expert ou alguém com competência, autoridade e credenciais semelhantes. Essa crítica à C. A. J. Coady (1992) é oferecida por Jennifer Lackey (2006, p. 179-81), na qual ela argumenta que: (a) o testemunho pode ser dado sem que haja uma questão disputada, (b) a definição de Coady não possibilita a diferença entre bom e mau testemunho, além de (c) não reconhecer que o testemunho pode ser uma fonte de crença e conhecimento para um

\footnotetext{
6 "According to Coady's NVT, we need only ask the former question since a statement will not count as a case of testimony unless it is potential evidence. Thus, it is impossible to have an unreliable testifier on Coady's model: a speaker would simply fail to testify if there weren't an objective connection between the statement that $p$ and that for which it is evidence" (LACKEY, 2006, p. 180).
} 
ouvinte, apesar da intenção do declarante em ser uma fonte epistêmica e (d) não reconhecer que um declarante pode testemunhar, apesar da necessidade epistêmica de seus ouvintes. Assumindo a explicação disjuntivista acerca da natureza do testemunho, o boato fica tipificado como um caso de testemunho genuíno.

Pode-se objetar contra (B3) que pessoas bem informadas podem endossar um boato. David Coady (2006) já havia chamado atenção para este aspecto. $O$ fato de toda justificação para o boato ser de segunda mão não significa não ter evidência para o boato. Embora a evidência de segunda mão possa ser mais fraca que a evidência de primeira mão, continua sendo evidência e fornecendo alguma base para o boato. Por outro lado, pode-se argumentar juntamente com David Coady (2012, p. 90-91) que os boatos podem aumentar a sua confiabilidade ao longo do tempo e da cadeia, visto que aqueles que ouvem os boatos podem avaliá-los de forma independente e ainda estar em condição de avaliar a confiabilidade dos propagadores.

\section{Boato como Testemunho sem Status Oficial}

De acordo com David Coady (2006, p.): “[a]s duas características (...) essenciais para uma comunicação constituir um boato são que ele deve ter passado por muitas mãos (ou lábios) e que ele tenha um status não oficial no tempo e local em questão"7.

Pode-se formalizar as ideias de David Coady da seguinte maneira:

$\left[\mathrm{B}_{2}\right]$ : $\mathrm{S}$ espalha um boato $\mathrm{B}$ se e só se:

(B1) S comunica uma proposição $p$;

(B2) $p$ é espalhada em uma larga cadeia;

(B3) $p$ tem status não oficial.

A condição (B1) parece qualificar o boato como um tipo de testemunho. De acordo com a explicação disjuntiva acerca do testemunho, proposta por Jennifer Lackey (2006, p. 187), alguém testemunha que $p$ "ao fazer um ato comunicacional"8. Essa explicação acerca da natureza do testemunho é muito diferente daquela oferecida por C. A. J. Coady (1992), visto que

\footnotetext{
7 "The two features that I have said are essential for a communication to constitute a rumour are that it has passed through many hands (or lips), and that it has unofficial status at the time and place in question" (COADY, 2006, p. 49). Ele observa na introdução que "In the final section I argue that these individually necessary conditions are also jointly sufficient" (COADY, 2006, p. 42).

8 "In my proposal, I shall focus on the notions of an act of communication, a, conveying the information that p. (...) In order to avoid the difficulties with this approach, I am construing the concept of an act of communication broadly so that it does not require that the speaker intend to communicate to others; instead, it requires merely that the speaker intend to express communicable content" (LACKEY, 2006, p. 187).
} 
essa não conjuga a metafísica e a epistemologia do testemunho. Antes, essa permite haver testemunho confiável e inconfiável. Ainda que boatos fossem inconfiáveis, o que não é necessariamente verdadeiro para David Coady $^{9}$, eles ainda seriam casos de testemunho genuíno.

A condição (B2), além de diferenciar o boato de outros tipos de comunicação informal de âmbito mais restrito, como é o caso da fofoca, ela vincula o boato aos 'grandes números'. David Coady (2006, p. 42) observa que "o número de informantes por meio do qual um boato se espalhou deve ser bastante grande. (...) Em geral, quanto mais um boato se espalhou, mais plenamente ele merece o nome"10. Todavia, ele reconhece que quando afirma "muitas mãos (ou lábios)", o termo "muitas" é "um quantificador apropriadamente vago"11.

A condição (B3) exclui qualquer comunicação por parte de um órgão governamental ou de uma rede de TV e comunicação como sendo um boato. Para Coady (2006, p. 48), " os boatos são essencialmente coisas não-oficiais. Nenhuma declaração pública de um governo ou de uma agência governamental, por exemplo, não importa o quão longe está de um relato da testemunha original, poderia ser um boato ${ }^{12 " . ~ U m ~ c a s o ~}$ diferente seria o governo confirmar um boato, como por exemplo, o aumento em mais de 3\% no preço da gasolina. O governo, ao conferir um status oficial à informação, desqualificou-a como boato. Coady (2006, p. 49) observa também que a ausência de verificação oficial "não implica a presença de refutação oficial"13.

Pode-se objetar contra (B2). Falar do tamanho da cadeia é problemático. Imagine o boato em um vilarejo ou numa escola. O número de propagadores nesses ambientes não seria grande, talvez 50 ou 90 pessoas. Claro, podese pensar em escolas ou vilarejos maiores. Um boato poderia alcançar de boca em boca cerca de 600 ou de 1500 pessoas. Por outro lado, imagine um boato propagado amplamente no tempo e no espaço, via internet,

9 According to Coady, “(...) many rumours are credible (that is, it is rational to believe them), and that in general the fact that a proposition is rumoured to be true is evidence in favour of it being true" (COADY, 2006, p. 41-2).

10 “(...) the number of informants through which a rumour has spread must be quite large. (...) In general, the further a rumour has spread, the more fully it deserves the name" (COADY, 2006, p. 42).

11 "I take it to be an essential feature of a rumour that many (an appropriately vague quantifier) of the people spreading the rumour are interested in whether it is true, and are at least prepared to entertain the possibility that it is in fact true" (COADY, 2006, p. 45).

12 "Nonetheless it does contain the valuable insight that rumours are essentially unofficial things. No public statement by a government or a government agency, for example, no matter how far removed it was from an original eyewitness account, could be a rumour (though, of course, it could confirm a pre-existing rumour or be responsible for starting another rumour)" (COADY, 2006, p. 48).

13 "The absence of official verification is essential to a rumour, but that does not entail the presence of official refutation (or even denial)" (COADY, 2006, p. 49). 
por exemplo, que 'utilizamos apenas 10\% do nosso cérebro'. Quem sabe quantas pessoas reverberam e/ou já reverberaram esse boato? Mais de mil pessoas? Mais de um milhão de pessoas? O que seria uma larga cadeia? Parece haver uma diferença significativa entre 60 e um milhão de pessoas. Talvez não seja necessário nem interessante definir o boato pelo tamanho da cadeia de propagação.

\section{Boato como Testemunho sem Corroboração Independente}

De acordo com Axel Gelfert (2013, p. 771), boato é "[a] propagação de rumor aparentemente informativo, geralmente sobre um tópico de amplo interesse, e tipicamente comunicado por vias informais na ausência de corroboração independente, ou de evidências de primeira-mão ou de fontes oficiais (autorizadas)"14.

Pode-se formalizar as ideias de Axel Gelfert da seguinte maneira:

$\left[\mathrm{B}_{3}\right]$ : S espalha um boato $\mathrm{B}$ se e só se:

(B1) S transmite uma proposição $p$;

(B2) $p$ não é corroborada, de forma independente, ou por evidência de primeira-mão ou por fonte oficial (autorizada).

A condição (B1) caracteriza o boato como um caso de testemunho informal. Gelfert observa que o boato seria caracterizado como um caso de "rumor que é aparentemente propagado e apresentado como informativo - sendo o seu status como rumor explicitado, ou não, para o destinatário"15 (GELFERT, 2013, p. 771).

A condição (B2) foca na ausência de evidência independente, como explica Gelfert no excerto abaixo:

Em vez da falta de evidência em geral, é a falta de confirmação independente por fontes autorizadas que é característica do boato: Às vezes nós temos evidência empírica de primeira mão suficiente à nossa disposição para chegar a um juízo ponderado sobre uma instancia do rumor que nos deparamos, mas, muitas vezes, precisamos confiar no testemunho institucional - por exemplo, trabalhos de referência, especialistas, enciclopédias, organismos científicos e fontes confiáveis de notícias - para confirmação autorizada. Quando uma (ou ambas) dessas evidências - evidência de primeira mão e fontes oficiais

\footnotetext{
14 "Rumour, thus, may be described as the propagation of ostensibly informative hearsay, usually on a topic of broader interest, and typically communicated via informal pathways in the absence of independent corroboration by either firsthand evidence or official (authoritative) sources" (GELFERT, 2013, p. 771). This account appears also in Axel Gelfert (2014).

15 " (...) it would therefore be preferable to characterize rumor as hearsay that is ostensibly propagated and presented as informative - whether or not its status as hearsay is made explicit to the recipient (...)" (GELFERT, 2013, p. 771).
} 
independentes - são inacessíveis ou contradizem uma a outra, as condições são conducentes ao desenvolvimento e disseminação de boatos (GELFERT, 2013, p. 771) ${ }^{16}$.

CASo 1. Considere o caso do secretário que escuta a conversa atrás da porta. O Sr. Souza é um dos cinco membros da diretoria executiva de uma fábrica de calçados. Enquanto o Sr. Souza lê para os demais membros da diretoria o projeto final sobre os designs dos calcados e a estratégia de vendas para o próximo ano a portas fechadas, o Sr. Silva, um secretário muito curioso, que não desempenha qualquer papel junto a essa diretoria, escuta atrás da porta parte da leitura do projeto final. No dia seguinte, o Sr. Silva diz para o seu colega de trabalho: Ouvi dizer que (P) "os sapatos serão mais coloridos no próximo ano". O seu colega, então, pergunta: Como você obteve essa informação? O Sr. Silva, com medo de receber alguma represália por ter escutado indevidamente atrás da porta, responde: Ouvi uma pessoa dizendo para outra enquanto eu passava pelo andar. O seu colega de trabalho, sem saber qual é a fonte original da informação e suspeitando que tal informação já está circulando entre os colegas de trabalho, resolve comunicá-la a outro colega que trabalha na recepção da empresa.

Esse parece ser um caso típico de propagação de boato. Todavia, ninguém contou ao Sr. Silva que (P) "os sapatos serão mais coloridos no próximo ano". Ele escutou a leitura do projeto final, ainda que indevidamente, em primeira mão. A evidência que o Sr. Silva tem para a informação P é a mesma que a diretoria possui. A informação P está contida no projeto final. Contudo, o Sr. Silva não revelou a ninguém a fonte da informação. Nesse caso o Sr. Silva tem evidência de primeira mão, mas não a utiliza para corroborar a informação P. Considere agora uma variação do caso 1: 'o caso do secretário que escuta a conversa atrás da porta'.

CASO 2. Considere agora que o Sr. Silva após ter escutado atrás da porta parte da leitura do projeto final e escutado que (P) "os sapatos serão mais coloridos no próximo ano", resolve não contar nada a ninguém. Todavia, após uma semana, várias pessoas estão espalhando a informação $P$ informalmente, sem que o Sr. Silva saiba qual é a fonte original da

16 "Rather than lack of evidence in general, it is the lack of independent confirmation by authoritative sources which is characteristic of rumor: sometimes we have enough firsthand empirical evidence at our disposal to come to a considered judgment regarding an instance of hearsay we encounter, but often we need to rely on institutional testimony - e.g., reference works, experts, encyclopedias, scientific bodies, and trusted news sources - for authoritative confirmation. When either (or both) of these - independent first-hand evidence and official sources - are unavailable, or contradict one another, conditions are conducive to the development and spread of rumor" (GELFERT, 2013, p. 771). 
cadeia de propagação. Ele resolve, então, contar ao seu colega que ele tem evidência de primeira mão que corrobora a informação P. Seu colega passa a adicionar à informação $\mathrm{P}$ outra informação: (Q) "Meu colega escutou que P quando estavam lendo o projeto final em primeira mão". As pessoas estão espalhando agora que ' $\mathrm{P} \& \mathrm{Q}$ '.

Nesse segundo caso, ninguém sabe dizer qual é a fonte original do boato. Contudo, o Sr. Silva não somente tem evidência de primeira mão para a informação $\mathrm{P}$, mas também a utiliza para corroborar a informação $\mathrm{P}$ diante de seu colega. A informação P é corroborada independentemente pelo Sr. Silva com evidência de primeira mão. Todavia, ainda parece ser um boato. O Sr. Silva escutou apenas parte da leitura do projeto final. Talvez outras informações contidas no projeto final possam anular a informação P. Embora o Sr. Silva tenha corroborado independentemente P com evidência de primeira mão, isso não desqualifica o caso como boato. A informação espalhada passa a ser 'P\&Q'. É como dizem "quem conta um conto, aumenta um ponto". Alguém pode pensar que o Sr. Silva não escutou tudo o que havia na seção do projeto final que continha a informação $\mathrm{P}$ ou que não escutou direito, ou, até mesmo, que estava inventando para ganhar atenção. Não haver corroboração independente de evidencia de primeira mão não parece ser uma condição necessária para constituir um boato.

\section{Boato como Testemunho sem Fonte Original}

Como foi visto, (a) C. A. J. Coady $(1992,2006)$ não considera o boato como um caso de testemunho genuíno, em virtude de assumir como pressuposto a visão estreita acerca da natureza do testemunho. A visão estreita acerca do testemunho parece ter vários problemas. Rejeitá-la em favor da visão disjuntivista acerca da natureza do testemunho parece ser vantajoso, sobretudo em vista de oferecer uma caracterização mais acurada sobre a natureza do boato; (b) David Coady $(2006,2012)$ embora entenda o boato como um caso de testemunho genuíno, defende como condição necessária que a informação p seja espalhada em uma larga cadeia. Além do problema da vaguidade, também não parece ser necessário que o boato seja espalhado em uma larga cadeia ou por um número grande de pessoas; (c) Axel Gelfert $(2013,2014)$ embora entenda o boato como um caso de testemunho genuíno e não coloque como condição necessária que ele seja propagado por um número grande de pessoas, assume como condição necessária que o boato não tenha corroboração independente de evidência de primeira mão. Todavia, isso pareceu não ser o caso, quando consideramos a variação (2) do caso do secretário que escuta a conversa atrás da porta. 
Diante disso, minha proposta é a seguinte:

$\left[\mathrm{B}_{4}\right]$ : $\mathrm{S}$ espalha um boato $\mathrm{B}$ se e só se:

(B1) S testemunha uma proposição $p$;

(B2) $p$ é espalhada em uma cadeia cuja fonte original foi perdida ou nunca existiu;

(B3) $p$ não tem confirmação de fonte oficial (autorizada).

A condição (B1) está aí para tipificar o boato como um caso de testemunho genuíno. Ao assumir como pressuposto a explicação disjuntivista acerca da natureza do testemunho, contempla-se casos em que alguém ouve uma conversa indevidamente e propaga o conteúdo informacional - casos semelhantes ao caso do secretário que escuta a conversa atrás da porta. A explicação disjuntivista parece não só apropriada para explicar quais fenômenos são casos de testemunho, mas também para explicar quais fenômenos são casos de boato. Boatos são casos particulares de testemunho informal. Outro aspecto a considerar é que boatos visam à crença, diferente de proposições ficcionais, como mitos, folclores e lendas urbanas. Boatos podem ser verdadeiros ou falsos. Mitos, folclores e lendas urbanas são narrativas apócrifas altamente estilizadas que visam à ação ou manutenção de costumes. Esse entendimento acerca da natureza dos boatos ganhou força com os estudos acerca da psicologia dos boatos de Robert H. Knapp em 1944 (p. 22-23), que classificou o boato como um "caso especial de comunicação informal".

A condição (B2) está aí para indicar que o propagador original da informação não é rastreado. Ninguém sabe onde a cadeia de propagação começou. Ninguém sabe se o primeiro propagador tinha evidência de primeira mão ou não. Um boato pode começar como fofoca, mexerico, falação etc. Talvez o boato tenha iniciado de uma especulação. Se não se é capaz de saber quem foi o propagador original, então não é possível avaliar a sua veracidade, competência e confiabilidade em relação ao seu testemunho. A falta de uma origem confiável é uma marca dos boatos. Essa condição contempla a perspectiva de estar em uma grande cadeia, embora isso não seja necessário. Se alguém rastrear a fonte original de propagação, então pode avaliar a fonte, e, consequentemente, deixa de configurar um boato.

A condição (B3) está aí para indicar que o boato é por definição não oficial. Não há uma fonte credenciada para corroborar a informação. Boatos tipicamente circulam por vias informais. Contudo, carecem da corroboração de alguma pessoa, grupo ou instituição que tenha tal autoridade. O termo "autoridade" aqui deve ser entendido como autoridade administrativa. Embora as pessoas esperem que a fonte 
oficial tenha também uma autoridade epistêmica sobre o domínio em questão, essa não é necessária. A autoridade epistêmica deveria sobrevir da autoridade administrativa. Pense em casos no qual o porta voz ou representante do grupo ou instituição tem a autoridade administrativa para fazer o pronunciamento, mas ele mesmo não tem a autoridade epistêmica sobre o conteúdo informacional que está divulgando. Pense, também, em casos de professores que estão deslocados da área na qual tem formação. Todos eles têm a autoridade administrativa para gerenciar suas classes, mas talvez alguns deles estejam atuando em um domínio distante da sua formação, no qual não lhe resta mais qualquer autoridade epistêmica genuína. Espera-se que a autoridade epistêmica venha junto com a autoridade administrativa nos casos de comunicação oficial por parte de fonte autorizada, todavia a autoridade epistêmica não é necessária. Ainda que um expert vá aos meios de comunicação para dirimir o boato. Se o expert não tiver uma credencial administrativa de expert, sua autoridade epistêmica reconhecida ou validada socialmente, seu pronunciamento não terá a força para dirimir o boato. Seu pronunciamento poderá ser considerado como sendo apenas mais um a "engrossar o caldo" do boato.

\section{Considerações finais}

A definição $\left[\mathrm{B}_{4}\right]$ incluiu o boato entre os casos de testemunho, diferente da definição $\left[\mathrm{B}_{1}\right]$, que pressupunha uma visão profundamente pessimista acerca da natureza e da epistemologia dos boatos. Embora $\left[\mathrm{B}_{4}\right]$ tenha abandonado a condição do grande número de propagadores, defendida por $\left[\mathrm{B}_{2}\right]$, ela não é incompatível com $\left[\mathrm{B}_{4}\right]$. Pode-se defender, sem problemas, que em muitos casos os boatos são espalhados entre muitas pessoas. Além disso, $\left[\mathrm{B}_{4}\right]$ impõe menos condições epistêmicas ao boato, diferente de $\left[\mathrm{B}_{3}\right]$, sem deixar de capturar as intuições fundamentais acerca do fenômeno, como o anonimato do propagador original e a falta de confirmação oficial. A definição $\left[\mathrm{B}_{4}\right]$ é compatível, inclusive, com uma defesa do status epistêmico positivo (justificação testemunhal) dos boatos em determinadas situações.

\section{Referências}

ALLPORT, G. W.; POSTMAN, L. The psychology of rumour. New York: Henry Holt \& Co., 1947.

COADY, C. A. J. "Pathologies of Testimony". In: LACKEY, J.; SOSA, E. (Eds.). The Epistemology of Testimony. Oxford: Oxford UP, 2006. p. 253-71.

COADY, C. A. J. Testimony: A Philosophical Study. Oxford: Clarendon Press, 1992. 
COADY, David. Rumour has it. International Journal of Applied Philosophy, 20 (2006), p. 41-53.

COADY, David. What to Believe Now: Applying Epistemology to Contemporary Issues. Chichester: Wiley-Blackwell, 2012.

GELFERT, A. Coverage-reliability, epistemic dependence, and the problem of rumorbased belief. Philosophia, 41 (2013), p. 763-786.

GELFERT, A. A critical introduction to testimony. Sydney (Australia): Bloomsbury, 2014.

KNAPP, R. H. Psychology of Rumor. The Public Opinion Quarterly, 8 (1944), p. 22-37.

LACKEY, J. The nature of testimony. Pacific Philosophical Quarterly, 87 (2006), p. 177-197.

SUNSTEIN, Cass. A verdade sobre os boatos - como se espalham e como acreditamos neles. Rio de Janeiro: ELSEVIER, 2010.

\section{Endereço postal:}

Programa de Pós-Graduação em Filosofia - PUCRS

Avenida Ipiranga, 6681 - Prédio 5

Porto Alegre, RS, Brasil

Data de recebimento: 25-11-2016

Data de aceite: 25-11-2016 